\title{
Exploration on Resettlement of Large and Medium Sized Hydropower Projects
}

\author{
Ren Rong ${ }^{1}$ Chen Jian-xi ${ }^{1}$ He Ming-zhang ${ }^{2}{\text { Xiao } \text { Cong }^{1} \text { Dong Kai-ling }}^{3}$ \\ Zhang Xue-mei ${ }^{*}$ \\ ${ }^{1}$ Chengdu University Chengdu Sichuan 610106 \\ ${ }^{2}$ The Yalong River Hydropower Development Co., Ltd. Chengdu Sichuan 610056 \\ ${ }^{3}$ Chengdu industry Career Technical College Chengdu Sichuan 610213
}

\begin{abstract}
This paper discusses the large and medium sized hydropower engineering migration and resettlement modes, analyzed the problems existing in China's large and medium sized hydropower project resettlement, and discusses the way to large and medium-sized hydropower project management of resettlement, such as establish social security system for reservoir migrants; improve the migration resettlement areas of infrastructure construction; to strengthen the training of skilled migrants; establish coordination mechanism for reservoir resettlement management and the development of society and economy.
\end{abstract}

Keywords: Large and medium sized hydropower projects Migrants Resettlement

\section{Resettlement of Large And Medium Sized Hydropower Projects}

\subsection{Classification of Large and Medium Sized Hydropower Projects}

Large and medium sized hydropower project resettlement divided into two kinds: One kind is located in the reservoir submerged line of rural residents, the land is submerged and relocation known as rural migrants; the other is the urban relocation, land expropriation and relocation of rural residents for two migrant, the research object of this paper contains both, also known as rural reservoir resettlement.

\subsection{Resettlement of Large and Medium Sized Hydropower Projects}

Resettlement of large and medium sized hydropower projects divided into living arrangements and production arrangements. The effect of production arrangements of migrants involved in the longterm development, and the effect of protection is for future life of the migrants. The production of reservoir resettlement mainly include agricultural resettlement, enterprise job resettlement, self occupation resettlement and social security resettlement. Agricultural resettlement mainly depend on local advantage of agriculture, land development, change land to garden. Enterprise job resettlement means migration resettlement area of enterprises to recruit migrants into factory. Self occupation resettlement means government one-time payment of cash grants to migrants, and the migrants find the job by themselves. Social security resettlement means government give the rural migrants that male over 60, female over 55 for social endowment insurance.

\section{Problems in Resettlement of Large and Medium Sized Hydropower Projects}

\subsection{Migrants Lose Land and Unemployment}

2.1.1 Migrants lose land. Hydropower project construction for land acquisition, deprived the main production and living materials of migrants, the migration system has lost the social and economic production of building foundation, if the resettlement area did not receive reasonable compensation, migrants will loss land. 
2.1.2Migrants unemployment. Migrants were forced to unemployment after losing land. First, losing land make rural migrants not only lost the opportunity to farm but also lost the chance to engage part-time job. Second, no land for urban and rural population has lost the opportunity to work on farm owned or rented, and lost the opportunity to work in their own town. Third, affected by the flooded, the industrial and mining enterprises have to inundate area or relocate from the closure, the bankruptcy of the enterprise workers are unemployed. Forth, submerged area community service facilities, small private enterprises in the migration cannot be rebuilt, which leads to migrant unemployment. Fifth, because lack of land, some resettlement area will likely to lead surplus of rural labor, which make it difficult to transform the surplus labor to urban or second, third industries.

\subsection{Social Networks of Migrants are Destroyed and the Migration is Marginalized}

2.2.1. Social networks of migrants are destroyed. The formation of social networks is a long and complex social process, including the relationship among family members, colleagues, friends, religious groups, neighborhood, and so on. Non voluntary migration disturbs the original social structure of the migrants, which makes the community decomposition and cracking, the platform of social organization and interpersonal relationship is destroyed, and the relative relationship is weakened.

2.2.2. The migration is marginalized. Marginalization is due to a decline in income and migrants change to a low level of social status. Due to the change of the mode of production, many immigrants in the new resettlement area cannot use their previous skills, human capital loss or become negative and useless, this caused the economic marginalization. Society, psychological marginalization and economic marginalization is accompanied, mainly for the change of social environment, lack of adaptability of lead to a loss of confidence in the community, become demoralized and sense of injustice intensified, psychological extreme fragility.

\subsection{Resettlement Area of Infrastructure is not Perfect}

Hydropower project resettlement is mainly based on agricultural resettlement, the government unified planning, the way to build houses. The low rural economic development level and the low level of life, poor quality of migrants, and the limited public goods investment may lead to resettlement area infrastructure, life inconvenient, which cause a sense of gap to the migration, migrants for the resettlement feel dissatisfied.

\subsection{Reservoir Resettlement in Terms of Compensation is not Fair}

From the perspective of reservoir immigration history, most of the reservoir resettlement compensation is not in conformity with the requirements of fair value. 1980s years ago, the reservoir resettlement compensation standards are generally low, unable to meet the needs of the follow-up development of immigrants, resulting in a lot of problems, such as different compensation standards for different status of migrants, different compensation standards for different regions. Reservoir resettlement does not have enough funds to protect, it is difficult to achieve the proper placement of migrants, the destruction of the social and economic system cannot be restored.

\subsection{Large Number of Reservoir Resettlement}

Reservoir resettlement means reservoir migrants from migration area return to a secondary reservoir surroundings, the migration direction and resettlement of primary migration just in opposite directions. Reservoir resettlement is non effective resettlement for migrants, because government lack the reservoir migration policy and defects, the resettlement of migrants cannot survive, large number of migrants have to return. Large migration return has brought serious consequences, first return caused adverse economic, second reservoir resettlement caused the relocation of migrants for second times, and the second reservoir resettlement is usually in the surrounding reservoir resettlement. 
In China, the basic projects for the reservoir resettlement of the original primary migration and find the resettlement places are charged by government, then migrants move back are by their own, and move back for the second reservoir resettlement is likely to be by the government, but in most cases migrants move back are by their own. Second resettlement generally relatively simple, part of the funds required by the government, or completely by migrants themselves. Therefore, migration has exhausted the initial payment of compensation, and they also ask for the government put forward the relocation of migrants and requires more funds for resettlement. Secondly, the migration around the reservoir caused the population mechanical growth, the reservoir area is difficult to coordinate the development. Migration is not only beyond the scope of environmental capacity of the reservoir area, but also caused the tension of interpersonal relationship. Return migration began to snatch the homestead, seizure of farmland, illegal harvesting after came near to rely on migration crops, cut down their trees, make the conflict between the nearest and the migration to the nearest intensified. We can say that in the reservoir area of the reality of the environment is very limited capacity for the reservoir, the reservoir area surrounding are a large number of migrants moved back to the area where there is a contradiction between people and nature, people and people. And the living standards of migrants returned to a serious decline in the quality of life. The quality of life in the presence of migrants is embodied in the aspects of income sources, ration, housing and the degree of stability of life. The most fundamental reason is the survival of reservoir migrants, and the defects of the reservoir resettlement policy are the direct reasons for the survival difficulties.

\section{Exploration on ResetTlement of LARge AND Medium Sized Hydropower PROJECTS}

3.1. Establish social security system for reservoir resettlement. Strictly implementation of relevant national policies, improve and enhance post resettlement support, take all factors into consideration and arrange the production and living of migration and resettlement population, increase input to the resettlement, establish social security system of reservoir migrants, put more migrants into the category of social security.

3.2. Improve the construction of infrastructure resettlement area. Governments at all levels should increase investment, strengthen construction of infrastructure of the resettlement area of water, electricity, gas, road construction, conditional place can be considered by the government unified planning, design, construction of infrastructure and complete migration resettlement area, and migration, thereby reducing the gap for the migrants, enhance the migrants to the satisfaction of the resettlement area.

3.3. Strengthen the training of migrant skills. Governments at all levels can be for migrants to carry out all kinds of techniques and skills training to improve the placement of migration survival skills and social adaptability so they can in the resettlement areas to find suitable for their survival and improve their standard of living, coordinate their relationships, achieve social network construction and reorganization, promote the resettlement area of social stability and harmony.

3.4. Establish a coordination mechanism of reservoir resettlement management and the development of society and economy.

Reservoir resettlement management is a people-oriented management activity, reservoir resettlement management should be coordinated with social and economic development. Therefore we should follow the people-oriented, according to local conditions, economic and effective, sustainable development, development of migration principles, establish the coordination mechanism of reservoir resettlement management and the development of society and economy (see chart), to promote the improvement of the living standards of migration and resettlement area. 


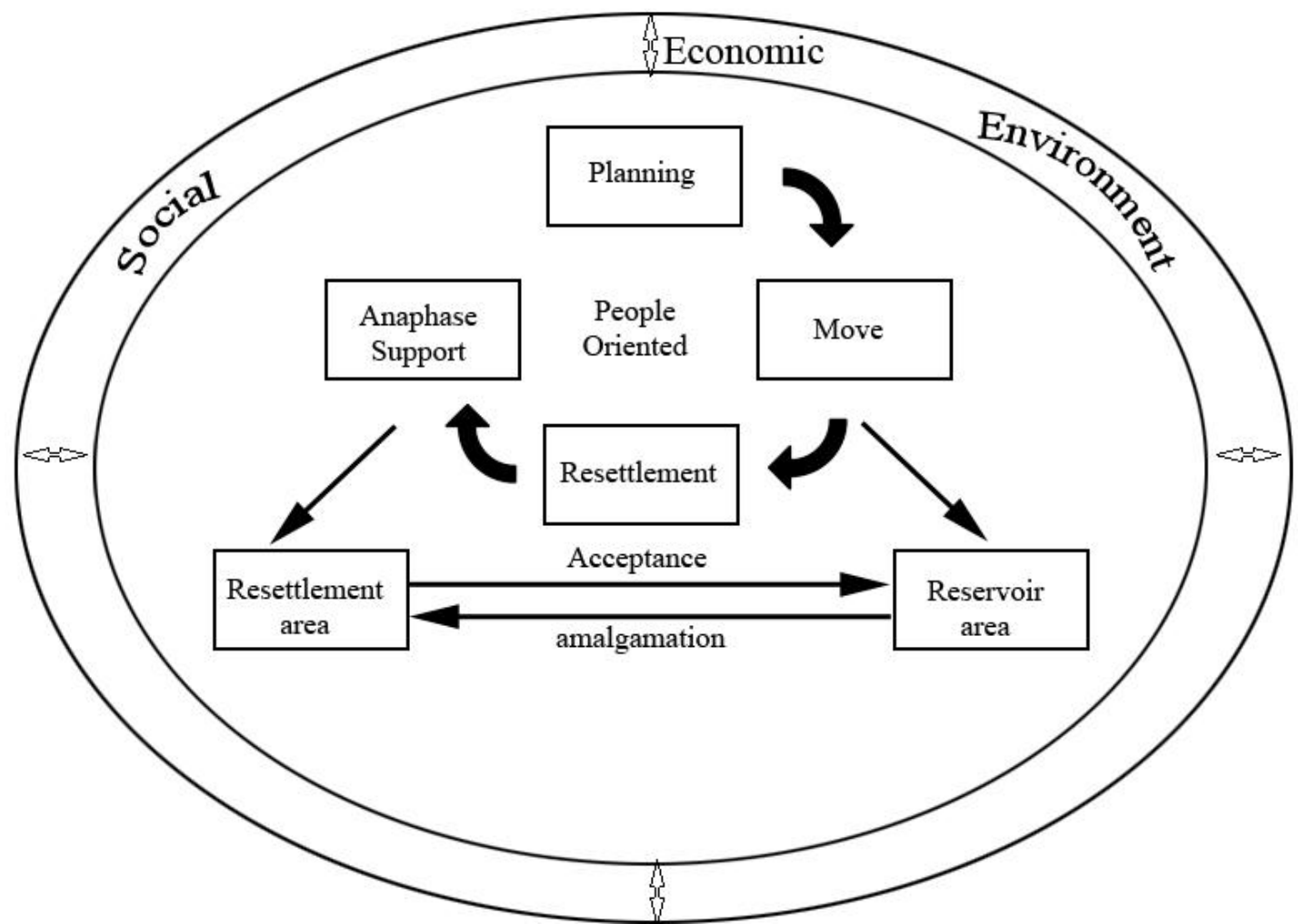

Figure1. Establish the Coordination Mechanism of Reservoir Resettlement Management and Social Economic Development

Note: This paper is one of the research results of Sichuan provincial science and Technology Department of the soft science project "based on the livelihood of the people" perspective of the large and medium sized hydropower project resettlement social management innovation, research (project number: 2014ZR0127).

\section{REFERENCES}

Cai Meng-sheng, Wei Yong, China dream of reservoir migration: building a better and happier life, Lao Qu Jian She, 2014, (18):35-37

Song Yong, Concept and classification of Hydropower Project Resettlement, Heilongjiang Science and Technology of Water Conservancy2013,( 9 ) :186-188

Liang Fu-qing, Thoughts and Countermeasures on the management of social stability of reservoir resettlement, Journal of China Three Gorges University ( Humanities \& Social Sciences) 2014,(1)

Fang Chang-rong, Current situation and development of resettlement management system for large and medium sized hydropower projects, Yangtze River, 2013(12):42-45

Zhu Tian-shu, Analysis and Countermeasures on the stability of reservoir resettlement, Henan Water Resources \& South-to-North Water Diversion, 2011,(19):25-27

Wang Zhen-tao, Guo Dong-qin, Research on the moral issues of reservoir resettlement in China. Journal of Yangtze Normal University, Journal of Yangtze Normal University, 2011, (6):60-63

Wei Xian-chao, Wu Zhuang-hai, Problems and treatment measures of reservoir resettlement, Pearl River, 2010,(5):3-6

Yin Hai-bo, Economic Analysis on asymmetric information of reservoir resettlement, Journal of Economics of Water Resources, 2010,(6):20-22

He Jian-yuan, Reservoir resettlement management and coordinated development mechanism of social economy, water resources planning and design, 2008, (3):9-12

Shen Ji-yong, Qiang Mao-shan, Zeng Rui-jie, On investigation support for resettlement and later rural reservoir, Yellow River, 2008,(8):8-9

Li Dan, Sun Ai-fen, The particularity of hydropower resettlement in Ethnic Minority Areas -- a survey of ethnic minorities in Sichuan, Heilongjiang National Series, 2007,(4):18-20

Sun Zhong-gen, Yang Wen-jian, Discussion on the establishment of social security system for reservoir resettlement, Yangtze River, 2007, (6):93-95 
Wang Hui, Chinese present age reservoir immigrant policy comparative analysis, Master Thesis of Huazhong Normal University [D], 2006.7-15

Cui Guang-ping, On the improvement of fair compensation of reservoir resettlement and its legislation, Journal of Economics of Water Resources, 2003,(3):57-60

\section{Authors' Biography}

Correspondence author Zhang Xue-mei (1965- ), female, doctor, Professor, master tutor, Chengdu University Professor, main research direction: enterprise management. Published papers 54, presided over the provincial (Department) level research projects 24, the main research 18; the publication of monographs and teaching materials 8 .

Ren Rong (1980- ), female, Assistant Professor, master, major research direction: public management, published 3 papers in 2 research projects, participate in compiling works 2. 